\title{
Multivariate Analysis of MRI Biomarkers for Predicting Neurologic Impairment in Cervical Spinal Cord Injury
}

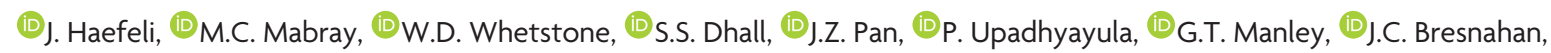
(1) M.S. Beattie, Aㅗ. Ferguson, and (1).F. Talbott

\begin{abstract}
BACKGROUND AND PURPOSE: Acute markers of spinal cord injury are essential for both diagnostic and prognostic purposes. The goal of this study was to assess the relationship between early MR imaging biomarkers after acute cervical spinal cord injury and to evaluate their predictive validity of neurologic impairment.
\end{abstract}

MATERIALS AND METHODS: We performed a retrospective cohort study of 95 patients with acute spinal cord injury and preoperative MR imaging within 24 hours of injury. The American Spinal Injury Association Impairment Scale was used as our primary outcome measure to define neurologic impairment. We assessed several MR imaging features of injury, including axial grade (Brain and Spinal Injury Center score), sagittal grade, length of injury, maximum canal compromise, and maximum spinal cord compression. Data-driven nonlinear principal component analysis was followed by correlation and optimal-scaled multiple variable regression to predict neurologic impairment.

RESULTS: Nonlinear principal component analysis identified 2 clusters of MR imaging variables related to 1) measures of intrinsic cord signal abnormality and 2) measures of extrinsic cord compression. Neurologic impairment was best accounted for by MR imaging measures of intrinsic cord signal abnormality, with axial grade representing the most accurate predictor of short-term impairment, even when correcting for surgical decompression and degree of cord compression.

CONCLUSIONS: This study demonstrates the utility of applying nonlinear principal component analysis for defining the relationship between MR imaging biomarkers in a complex clinical syndrome of cervical spinal cord injury. Of the assessed imaging biomarkers, the intrinsic measures of cord signal abnormality were most predictive of neurologic impairment in acute spinal cord injury, highlighting the value of axial T2 MR imaging.

ABBREVIATIONS: AIS = American Spinal Injury Association Impairment Scale; BASIC = Brain and Spinal Injury Center; MCC = maximum canal compromise; $\mathrm{MSCC}=$ maximum spinal cord compression; $\mathrm{NL}-\mathrm{PCA}=$ nonlinear principal component analysis; $\mathrm{PC}=$ principal component; $\mathrm{SCl}=$ spinal cord injury

$E^{a}$ arly biomarkers of spinal cord injury (SCI) are essential during the acute phase of injury, a time when crucial management decisions are made and a period of great prognostic anxiety for patients

Received August 1, 2016; accepted after revision October 4.

From the Departments of Neurological Surgery (J.H., S.S.D., P.U., G.T.M., J.C.B. M.S.B., A.R.F.), Radiology and Biomedical Imaging (M.C.M., J.F.T.), Emergency Medicine (W.D.W.), and Anesthesia and Perioperative Care (J.Z.P.), University of California San Francisco and Zuckerberg San Francisco General Hospital, San Francisco, California; Weill Institute for Neurosciences, Brain and Spinal Injury Center (J.H., W.D.W., S.S.D., J.Z.P., P.U., G.T.M., J.C.B., M.S.B., A.R.F., J.F.T.), San Francisco VA Medical Center (A.R.F.), San Francisco, California.

This work was supported by R01NS067092 (A.R.F.), R01NS088475 (A.R.F.), the Craig H. Neilsen Foundation (A.R.F., J.C.B.), Wings for Life Foundation (A.R.F.), and Department of Defense grant SC120259 (M.S.B., J.C.B.). M.C.M. was supported by a National Institutes of Health T32 Fellowship, 5T32EB001631-10. J.H. was supported by a Craig H. Neilsen Foundation fellowship (313739).

M.C.M. and J.H. contributed equally to this research and to the manuscript and are considered co-first authors.

Please address correspondence to Adam R. Ferguson, PhD, Department of Neurological Surgery, Zuckerberg San Francisco General Hospital, Building 1, Room 101,

San Francisco, CA 94110; e-mail: adam.ferguson@ucsf.edu and families. ${ }^{1-3}$ As emerging experimental therapies translate to the clinic, early biomarkers will also be important for patient selection and monitoring in clinical trials. Multiple potential MR imaging biomarkers exist to evaluate acute SCI. ${ }^{1,4-20}$ These measures primarily focus on the sagittal imaging plane, examining factors such as length of T2-hyperintense signal within the cord, whether abnormal signal is confined or spans multiple vertebral levels, presence of hemorrhage, and secondary markers of cord injury such as spinal cord compression and spinal canal compromise. ${ }^{1,5-22}$ The internal structure of the spinal cord, with predominantly longitudinally oriented WM tracts, suggests that the axial injury extent and WM sparing should also be strong predictors of outcome. This concept has been demonstrated in preclinical studies and recently in human studies introduc-

\footnotetext{
- Indicates open access to non-subscribers at www.ajnr.org

三 Indicates article with supplemental on-line tables.

Indicates article with supplemental on-line photo.

http://dx.doi.org/10.3174/ajnr.A5021
} 
ing an axial scoring system known as the Brain and Spinal Injury Center (BASIC) score. ${ }^{4,23-30}$ However, until now, it has been unclear how the axial grading relates to other imaging biomarkers of the sagittal plane and extrinsic compression measures.

The various MR imaging-based metrics have been shown to be reproducible, and all have some individual degree of predictive validity for clinical outcome. ${ }^{1,4-20}$ Here, we evaluated the relationships of these MR imaging metrics to each other and to neurologic impairment. We applied a data-driven tool, nonlinear principal component analysis (NL-PCA), to understand the relationship between different MR imaging biomarkers and assess their ability to predict neurologic impairment. NL-PCA detects statistical patterns, incorporating multiple variables independent of their scale and decomposing them into a smaller set representing multidimensional clusters of variables (principal components [PCs]) that covary. ${ }^{31,32}$ We then used nonlinear regression approaches to benchmark different MR imaging assessments against each other for predicting neurologic impairment at discharge. We hypothesized that MR imaging measures of acute cervical SCI would group together as a coherent multivariate PC ensemble and that distinct PCs (PC1, PC2, etc) would predict neurologic impairment. We intended 1) to provide insight into relationships between early MR imaging biomarkers after acute cervical SCI and 2) to provide an evaluation of the predictive validity of each individual measure of neurologic impairment.

\section{MATERIALS AND METHODS Study Cohort}

This study was HIPAA and institutional review board compliant. We performed a retrospective cohort study of patients with acute blunt cervical SCI evaluated at a Level I trauma center (Zuckerberg San Francisco General Hospital) from 2005 to 2014. Inclusion criteria were 1) blunt acute cervical SCI, 2) age $\geq 18$ years, 3 ) presurgical cervical spine MR imaging performed within 24 hours after injury, and 4) documented American Spinal Injury Association Impairment Scale (AIS) at both admission and discharge. Exclusion criteria were 1) penetrating SCI, 2) surgical decompression and/or fusion before MR imaging, 3) MR imaging that was too degraded by motion or other artifact such that images were nondiagnostic, and 4) preexisting surgical hardware. Of 212 patients initially identified, 95 patients met all inclusion and exclusion criteria and were included in the study. The data collected included sex and age, AIS at admission and discharge (as documented in the chart and performed by appropriately trained physiatrists and neurosurgeons), hours to MR imaging from time of injury, days to discharge, and whether surgical decompression of the cervical spine was performed before discharge. Fifty-two of the 95 patients included in this study were included in a cohort of patients as part of a previously published study. ${ }^{4}$ This prior, smaller study involved initial development and interrater reliability testing of the BASIC score, whereas the current study tests multiple MR imaging grading schemes against each other, and against neurologic outcome, by using multivariate statistical analysis.

\section{MR Imaging}

All MR imaging examinations were acquired on the same 1.5T Genesis Signa scanner (GE Healthcare, Milwaukee, Wisconsin). We assessed sagittal T2 FSE, sagittal T1, and axial T2 FSE sequences per- formed as part of our routine imaging protocol, with these sequences not substantially changing over the study interval. Additional sequences performed as part of our trauma imaging protocol were not evaluated. Sequences were performed with the following parameters (presented as mean \pm standard deviation from 10 randomly selected examinations): 1) for axial T2 FSE through the entire cervical spine: TR, $3798 \mathrm{~ms} \pm 586 \mathrm{~ms}$; TE, $102 \mathrm{~ms} \pm 6 \mathrm{~ms}$; section thickness, $3 \mathrm{~ms}$; echo-train length, $17 \pm 3.4$; in-plane FOV, $=160 \times 160 \mathrm{~mm}$ with a $512 \times 512$ matrix for nominal in-plane resolution of $0.31 \mathrm{~mm}^{2} ; 2$ ) for sagittal T2 FSE: TR, $3585 \mathrm{~ms} \pm 563 \mathrm{~ms}$; TE, $105 \mathrm{~ms} \pm 5 \mathrm{~ms}$; section thickness, $3 \mathrm{~mm}$; echo-train length, $17.1 \pm 3$; in-plane FOV, $200 \times$ $200 \mathrm{~mm}$; and 3) for sagittal T1: TR, $528 \mathrm{~ms} \pm 103 \mathrm{~ms}$; TE, $16 \mathrm{~ms} \pm 1.3$ $\mathrm{ms}$; section thickness, $3 \mathrm{~mm}$; echo-train length, $2.6 \pm 0.8$; and inplane FOV, $200 \times 200 \mathrm{~mm}$ with a $512 \times 512$ matrix for nominal in-plane resolution of $0.39 \mathrm{~mm}^{2}$.

\section{Image Analysis}

A neuroradiology fellow (M.C.M.) and attending physician (J.F.T.) performed consensus MR imaging ratings for all metrics while blinded to clinical outcome. The interrater reliability and BASIC axial MR imaging grading have been previously described as follows ${ }^{4,30}$ : grade 0 , no cord signal abnormality; grade 1 , T2 hyperintensity confined to GM; grade 2, intramedullary T2 hyperintensity extends beyond expected gray matter margins to involve spinal white matter, but does not involve entire transverse extent of the spinal cord; grade 3, T2 hyperintensity involving GM and some but not all of WM; grade 4, T2 hyperintensity involving the entire axial plane of the spinal cord; grade 5 , grade 3 injury with the addition of foci of T2 hypointensity consistent with hemorrhage. Sagittal grading was assigned as previously described: grade 1, no spinal cord signal abnormality; grade 2, single-level T2 hyperintensity; grade 3, >1 vertebral level T2 signal hyperintensity; grade 4, T2 signal hyperintensity with areas of hypointensity representing hemorrhage. ${ }^{1,19}$ The greatest length $(\mathrm{mm})$ of injury on sagittal T2 was measured as described in the National Institutes of Health/National Institute of Neurologic Disorders and Stroke SCI common data elements version 1.0. ${ }^{3}$ Maximum canal compromise (MCC) and maximum spinal cord compression (MSCC) assessed midsagittal images by dividing the anteroposterior diameter of the canal (on sagittal T1 for MCC) and the anteroposterior diameter of spinal cord (on sagittal T2 for MSCC) by the average of the canal or spinal cord above and below as previously described. $8,15,16,22$

\section{Multidimensional Analysis Workflow and Statistical Analysis}

NL-PCA assessed the relationship among MR imaging measures by incorporating pattern detection with optimal-scaling transformations to accommodate nonparametric, ordinal, and nonlinear relationships that are common in clinical assessment tools such as MR imaging scoring by a radiologist. ${ }^{33,34}$ Established decision rules defined the final dimensionality: Kaiser rule criterion of eigenvalue $>1$ and Cattell rule (ie, scree plot). ${ }^{33-36}$ Validity of MR imaging and PC scores for predicting AIS at discharge involved linear mixed model, Spearman rank correlation, and an optimal-scaled regression.

Receiver operating characteristic curves assessed sensitivity and specificity of MR imaging measures for predicting AIS at 
discharge by using a sliding scale (ie, AIS A versus B, C, D, E; AIS A, B versus C, D, E; AIS A, B, C versus D, E; and AIS A, B, C, D versus $E$ ), resulting in 4 separate receiver operating characteristic curves. In addition, we completed a supplementary analysis where

\section{Table 1: Patient characteristics ${ }^{\mathrm{a}}$}

\begin{tabular}{ll}
\hline Age & $57.91 \pm 18.15$ \\
Sex (M, F) & 67,28 \\
AIS at admission & $\mathrm{A}=26, \mathrm{~B}=9, \mathrm{C}=18, \mathrm{D}=42$ \\
AIS at discharge & $\mathrm{A}=17, \mathrm{~B}=3, \mathrm{C}=15, \mathrm{D}=41, \mathrm{E}=19$ \\
Time to MRI (hours) & $6.97 \pm 5.15$ \\
Time to discharge (days) & $25.15 \pm 35.31$ \\
Surgical decompression & Yes $=63, \mathrm{No}=32$ \\
\hline
\end{tabular}

${ }^{a}$ Values expressed as $N$ or mean $\pm S D$.

\section{Table 2: MRI scoring schemes}

\begin{tabular}{|c|c|}
\hline BASIC & $\begin{array}{c}\text { Ordinal } 0-4: 0=\text { normal; } 1=\mathrm{GM} \text { only; } 2=\text { some } \mathrm{WM} ; 3=\text { all WM } \\
\text { in plane; } 4=\text { with hemorrhage }\end{array}$ \\
\hline Sagittal grade & $\begin{array}{c}\text { Ordinal } 1-4: 1=\text { normal; } 2=\text { less than a VB; } 3=\text { longer than } 1 \mathrm{VB} ; \\
4=\text { with hemorrhage }\end{array}$ \\
\hline $\begin{array}{l}\text { Longitudinal extent of } \\
\text { T2 signal abnormality }\end{array}$ & Numeric $[\mathrm{mm}]$ \\
\hline $\mathrm{MCC}$ & $\begin{array}{l}\text { Numeric } M C C \%=1-\left\{D_{i} /\left[\left(D_{a}+D_{b}\right) / 2\right]\right\} \times 100 \% \\
\qquad D=\text { canal width }^{\mathrm{a}}\end{array}$ \\
\hline MSCC & $\begin{array}{c}\text { Numeric MSCC } \%=1-\left\{d_{i} /\left[\left(d_{a}+d_{b}\right) / 2\right]\right\} \times 100 \% \\
d=\text { spinal cord width }\end{array}$ \\
\hline
\end{tabular}

Note:-VB indicates vertebral body

${ }^{a}$ See Fig 1 for further description.

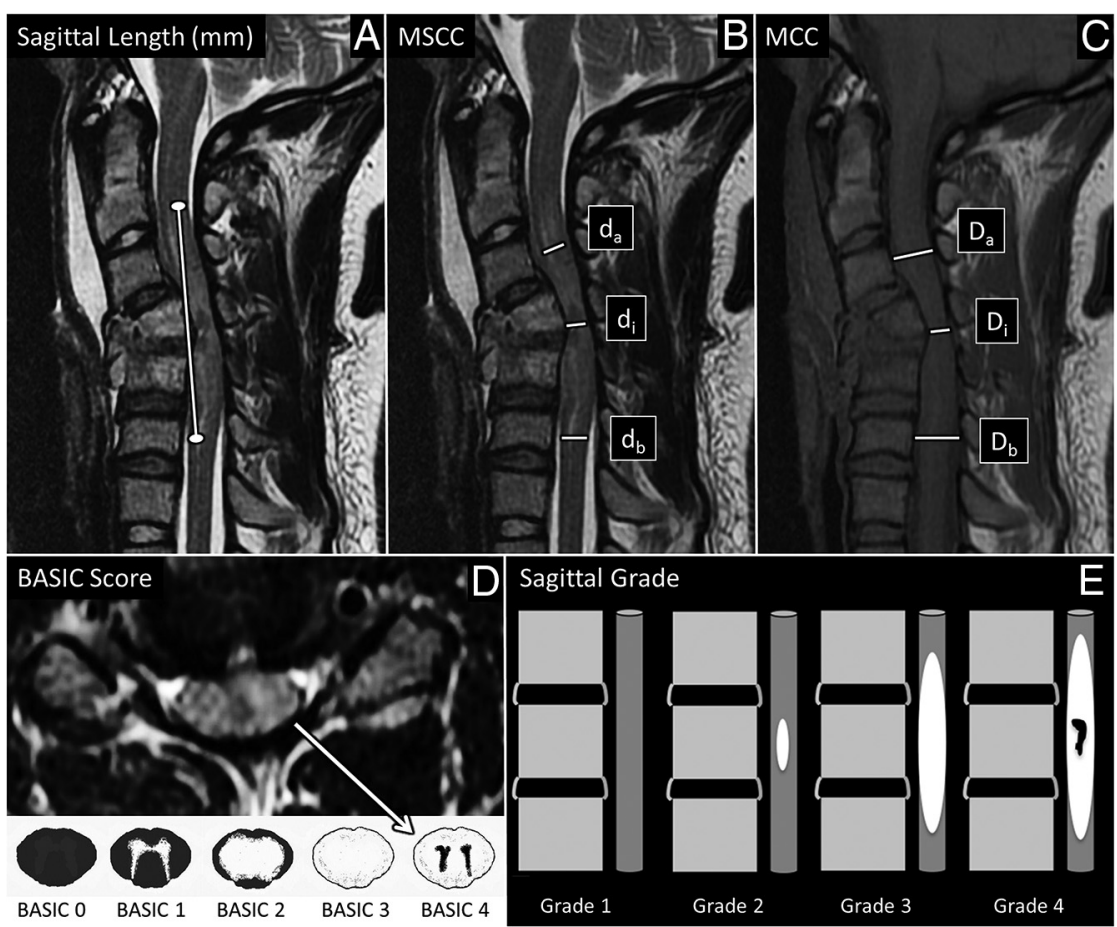

FIG 1. MR imaging-based metrics. $A$ and $B$, Sagittal T2-weighted MR imagings of the cervical spine of patients with acute $\mathrm{SCl}$ were used to measure the length of $\mathrm{T} 2$ signal hyperintensity in $\mathrm{mm}(A$, white line $)$ and to calculate MSCC $\left(B, 1-\left\{d_{i} /\left[\left(d_{a}+d_{b}\right) / 2\right]\right\} \times 100 \%\right)$. $d_{i}$ indicates distance of the spinal cord at the injury site; $d_{b}$, one segment below the injury site; $d_{2}$, one segment above the injury site. $C$, Sagittal T1-weighted image of the cervical spine demonstrating how we used this sequence to measure MCC $\left(1-\left\{D_{i} /\left[\left(D_{a}+D_{b}\right) / 2\right]\right\} \times 100 \%\right)$. $D_{i}$ indicates distance of the spinal canal at the injury site; $D_{b}$, one segment below the injury site; $D_{a}$, one segment above the injury site. $D$, The axial T2-weighted MR imaging of the cervical spine at the level of the epicenter of injury was used to define the BASIC score. Areas of macroscopic T2-hypointense hemorrhage are surrounded by hyperintense edema with no normal cord signal, consistent with BASIC grade 4 . BASIC axial grade cartoons are depicted in the lower panel. E, Shows cartoons of the sagittal grading system. Sag indicates sagittal. we compared adjacent groups. Because of the low number of paients in the AIS B subgroup $(n=3)$, AIS A and B were grouped gether as a motor complete group. We compared the areas unassess within the BASIC measure the optimal combination of scores to discriminate the different AIS groups. BASIC score discrimination of AIS at discharge. Statistical significance for all tests was set at $\alpha=.05$. All statistical analyses were performed in SPSS v.23 (IBM, Armonk, New York). Syndromic plots for the PC loadings were generated in custom-designed software in $\mathrm{R}$ (http://www.r-project.org/). ${ }^{37}$

\section{RESULTS}

Patient characteristics are listed in Table 1. MR imaging measurements are outlined in Table 2 and Fig 1. The relationships between the BASIC score and AIS at discharge are listed in Table 3. NLPCA demonstrated all imaging parameters loaded highly on PC1. PC2 discriminated MR imaging measures, with only MSCC and MCC showing high loadings (On-line Fig 1A). Statistical decision rules pruned the initial 5-dimensional NL-PCA solution to 2 dimensions (Online Fig $1 B$ ). The optimal-scaled transformation matrix revealed a high correlation between the lesion length, sagittal grade, and the BASIC score and, to a lesser extent, between the compression variables (MSCC and MCC) (Fig 2A). The loading patterns of the 2-dimensional NL-PCA solution are displayed in Fig 2B. PC1-2 accounted for $88.6 \%$ of the total variance in the dataset $\mathrm{PC1}$, 58.6\%; PC2, 30\%). All imaging variables loaded highly on PC1. Variance explained by PC1 represents convergence across all MR imaging variables. In contrast, PC2 mainly captures compression variables MSCC and MCC, representing divergence of the MR imaging variables of intrinsic cord signal abnormality.

In Fig $2 C$, individual $\mathrm{PC}$ scores are projected into PC1 and PC2 space, with each patient color-coded by AIS change and by AIS grade at discharge. Patients with higher scores on the PC1 axes have worse AIS at discharge. Confirming this, 
a linear mixed model revealed that $\mathrm{PC} 1$, but not $\mathrm{PC}$, significantly predicted AIS at discharge (PC1: $F=33.79, P<.001$; PC2: $F=$ $2.11, P=.086)$.

To compare predictive validity of PC1 and PC2 versus univariate MR imaging measures, we applied univariate nonparametric Spearman rank correlations for prediction of AIS at discharge (Table 4 and Fig 3). Based on Spearman rank correlation, variables of intrinsic cord signal abnormality (lesion length, sagittal

Table 3: BASIC score in relation to AIS at discharge $\mathrm{a}^{\mathrm{a}}$

\begin{tabular}{lcccccc}
\hline & AIS A & AIS B & AIS C & AIS D & AIS E & $\begin{array}{c}\text { Total } \\
\text { Patients }\end{array}$ \\
\hline BASIC 0 & & & & $1(7.7)$ & $12(92.3)$ & 13 \\
BASIC 1 & & $1(2.6)$ & $10(25.6)$ & $26(66.7)$ & $2(5.1)$ & 39 \\
BASIC 2 & & $12(70.6)$ & $5(29.4)$ & 17 \\
BASIC 3 & $7(43.8)$ & $2(12.5)$ & $5(31.3)$ & $2(12.5)$ & & 16 \\
BASIC 4 & $10(100)$ & & & & & 10 \\
\hline
\end{tabular}

${ }^{\mathrm{a}}$ Data presented as no. of patients (\%).
Optimal scaled transformation

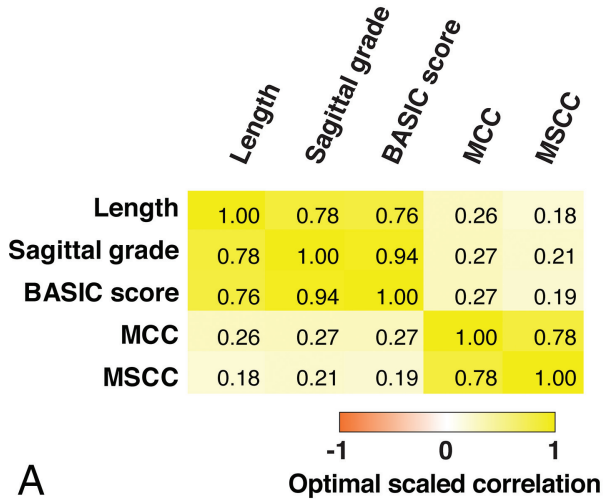

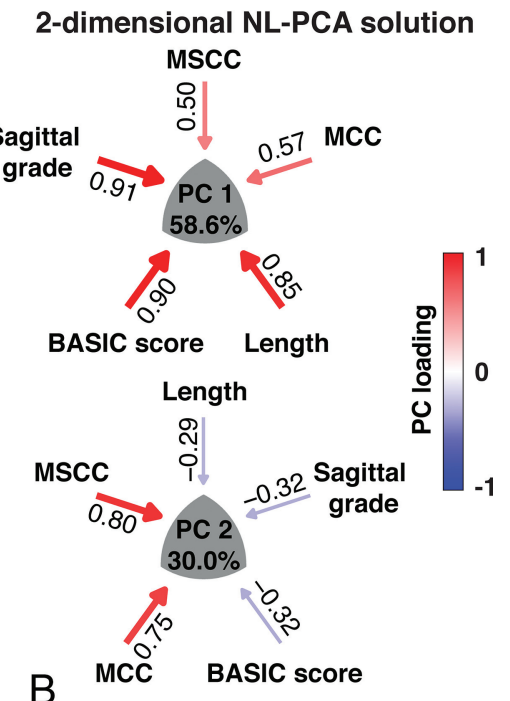

is

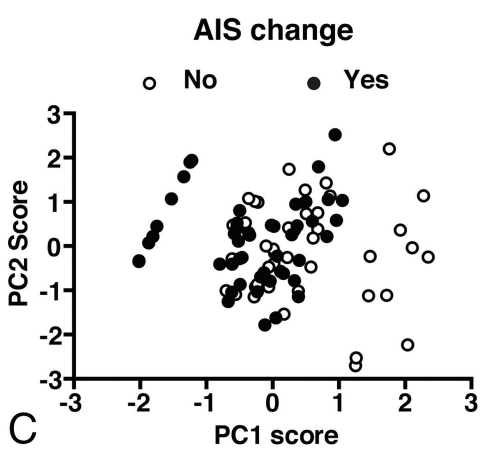

AIS at discharge

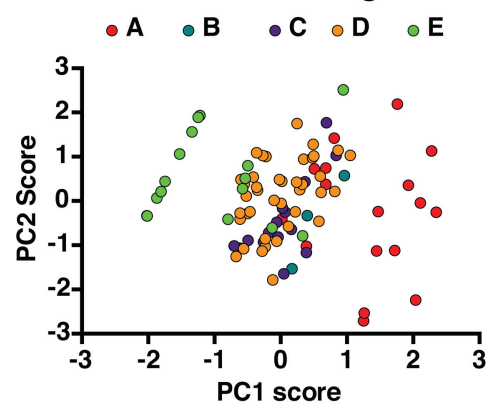

FIG 2. Results of the 2-dimensional NL-PCA. A, Heat map of the optimal-scaled transformation matrix of all MR imaging measures included in the NL-PCA. The matrix indicates all bivariate cross-correlations: yellow indicates a positive relationship and orange indicates a negative relationship. B, 2-dimensional NL-PCA solution. PCs reflect the clustered variance shared by the MR imaging measures and are represented by a convex triangle. The arrow gauge and the intensity of the color (red indicates a positive relationship and blue indicates a negative relationship) show the magnitude (ie, loading weights) of the correlation between each MR imaging measure and the PC. $C$, Bi-plots of individual patients $(n=95)$ in the 2-dimensional space described by $\mathrm{PCl}$ and $\mathrm{PC}$. In the top left corner, the extracted bi-plot is displayed. In the left graph, the same bi-plot is color-coded by AIS change (ie, AIS change from admission to discharge) and is color-coded in the right graph by AIS at discharge. PCA indicates principal component analysis. grade, BASIC score) and both PC1 and PC2 predicted AIS at disarge. Neither MSCC nor MCC significantly correlated with AIS at correlation with AIS at discharge $(\rho=0.22)$.

We used optimal-scaled regression to benchmark the predicvalidity of MR imaging measures against each other. An adAIS at discharge $(P<.01)$.

We next benchmarked how individual MR imaging measures perform in predicting AIS at discharge compared with AIS at admission. Not surprisingly, AIS at admission showed a strong positive correlation with AIS at discharge by Spearman rank correlation $(\rho=0.82, P<.01)$. Optimalscaling regression revealed that BASIC score and AIS at admission were the only significant predictors of AIS at discharge (both $P<.01)($ On-line Table 1$)$.

We were concerned that BASIC prediction of AIS at discharge may be confounded by the decision to perform surgical decompression, which could also influence outcome. To test this, we performed 2 additional waves of analysis. First, we tested whether BASIC score significantly predicted the decision to perform surgical decompression by using a generalized linear model. BASIC score significantly predicted surgical decompression decision-making (Wald $\chi^{2}=$ $9.00, P=.003$ ). To test whether this confounded BASIC's predictive validity for AIS at discharge, we reran the generalized linear model with an interaction term, testing whether BASIC and surgical decompression were statistically entangled. This analysis maintained the significant predictive main effect of BASIC on AIS (Wald $\chi^{2}=34.92, P<.001$ ). Furthermore, undergoing decompression surgery was not a significant predictor of AIS at discharge (Wald $\chi^{2}=0.17$, $P=.68$ ), nor was there a significant interaction between BASIC and decompression surgery (Wald $\chi^{2}=1.58, P=$ .66). Similarly, we wanted to assess if BASIC significantly predicts AIS at discharge after correcting for MSCC. Using the same analysis tools, the predictive validity of BASIC was maintained $(F=$ $30.69, P<.001$ ), and there was no interaction effect between AIS at discharge and $\operatorname{MSCC}(F=0.79, P=.53)$.

The sensitivity and specificity (receiver operating characteristic and area under the curve) of the MR imaging 
Table 4: Predicting AIS at discharge-Spearman rank correlation and optimal scaling regression results

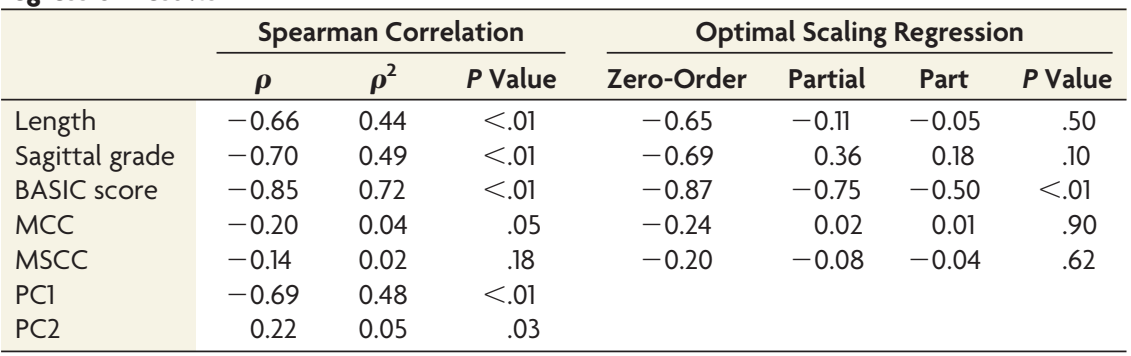
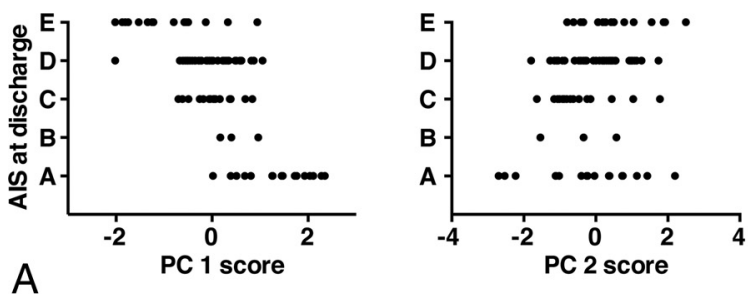

A
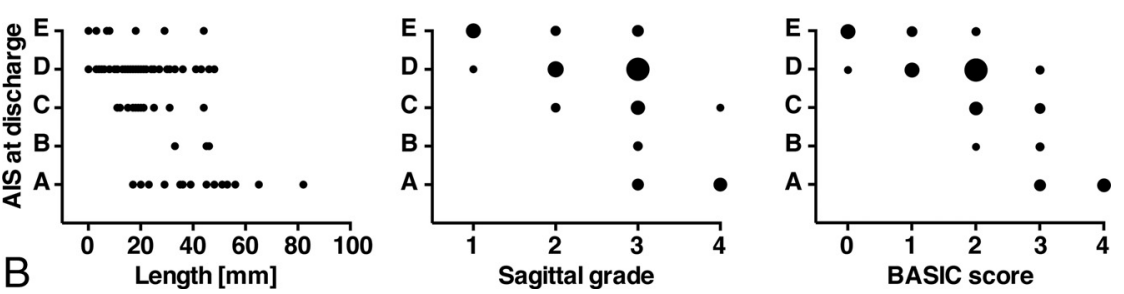

FIG 3. Multivariate (PCS) and univariate prediction of $A I S$ at discharge. $A, P C l$ was negatively correlated with AIS at discharge, and PC2 showed a weak positive correlation. $B$, The length of the lesion, the sagittal grade, and the BASIC score showed a negative correlation with AIS at discharge. Note that because of the ordinal scale of the BASIC score and the sagittal grade, some subjects coincide on the same value. The number of subjects within each sphere is represented by the size of the spheres. Only scatterplots of the statistically significant correlations between the MR imaging measures and AIS at discharge are displayed.

measures in predicting AIS at discharge are shown in Fig 4 (AIS sliding scale). Supporting previous analysis, the length, sagittal grade, and BASIC score predicted AIS at discharge, with their areas under the curve statistically superior to random guessing (Table 5). BASIC consistently had the highest area under the curve in comparison with the other MR imaging measures. In a supplementary analysis, we tested how well the MR imaging measures can discern adjacent AIS categories. The results are shown in On-line Table 2. Similar to the sliding scale results, BASIC consistently had the highest area under the curve for distinguishing both severe and mild AIS categories in comparison with the other MR imaging measures.

Finally, to assess discriminative value score subcategories, we applied a linear discriminant function analysis. This supervised pattern detection approach discovers the optimal combination of scores to discriminate the different AIS groups. The full BASIC score had the largest absolute correlation with the canonical discriminant function for AIS, suggesting that the full 5-point BASIC score performs better than truncated scoring schemes (0.962). The full BASIC score outperformed both the simple dichotomous score (lesion versus no lesion, with BASIC $0=$ no lesion and BASIC $1-4=$ any lesion; 0.388) and a 3 -point scale merging BASIC score subcategories $1-3$ into 1 category (BASIC $0=$ no lesion, BASIC 1-3 = nonhemorrhagic lesion, BASIC $4=$ hemor- rhagic lesion; 0.639). A second discriminant function analysis included only patients with a BASIC score of 1-3 (ie, those patients with nonhemorrhagic intramedullary $\mathrm{T} 2$ signal abnormality) to define the prognostic value of BASIC in this specific subpopulation. BASIC had the largest absolute correlation with the discriminative function (0.991), followed by the length of the lesion (0.416).

\section{DISCUSSION}

We applied data-driven multivariate analytic techniques to evaluate how multiple MR imaging-derived metrics relate to each other and to short-term impairment when applied to a group of 95 patients with acute blunt cervical SCI. We identified 2 principal components ( $\mathrm{PC} 1$ and PC2) that explained $88.6 \%$ of the total variance in the dataset. Measures of intrinsic spinal cord signal abnormality had the highest positive loading on PC1, whereas measures of extrinsic cord compression had more modest positive loading. Both the BASIC score and sagittal grade had greater correlation with outcome than PC1, whereas BASIC score was the only univariate MR imaging measure to correlate with outcome when correcting for differences in data measurement scales. The present results support the prognostic relevance of the BASIC score compared with other MR imaging measures of SCI.

Although all imaging variables loaded positively on PC1, PC2 was more discriminatory in nature, segregating structural measures of compression from variables reflecting intrinsic cord signal abnormality. PC2 had a weakly positive correlation with AIS ( $\rho=0.22, P=.03$ ), whereas measures of extrinsic compression had no significant correlation with outcome. These findings demonstrate the discriminant validity of NL-PCA and highlight the split between MR imaging measures of intrinsic cord signal abnormality and structural measures of compression. ${ }^{30}$ Structural measures of compression thus have a complex relationship with outcome. The present data do not necessarily conflict with prior work examining the predictive validity of MSCC in acute SCI. ${ }^{8,15,16,21,22}$ Miyanji and colleagues ${ }^{8}$ showed that MSCC was a key predictor of neurologic recovery after traumatic SCI. In that study, outcome for patients with SCI was dichotomized into complete and incomplete categories, whereas we have used the more granular 5-point AIS grading scale. In addition, after correcting for baseline neurologic status, only intrinsic measures of SCI significantly correlated with neurologic recovery, findings consistent with the present results. ${ }^{8}$

Receiver operating characteristic analysis confirmed that of the imaging variables examined, the BASIC score was the most accurate for predicting short-term impairment. We were con- 
AIS A vs. B,C,D,E

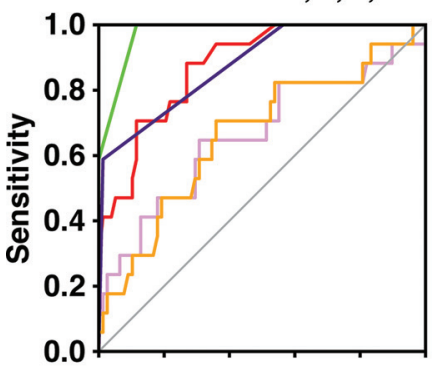

AIS A,B,C vs. D,E

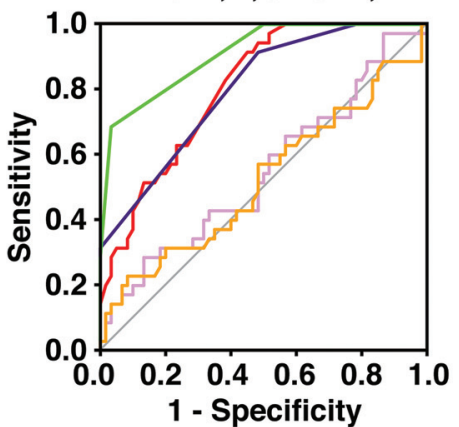

1.00
AIS A,B vs. C,D,E

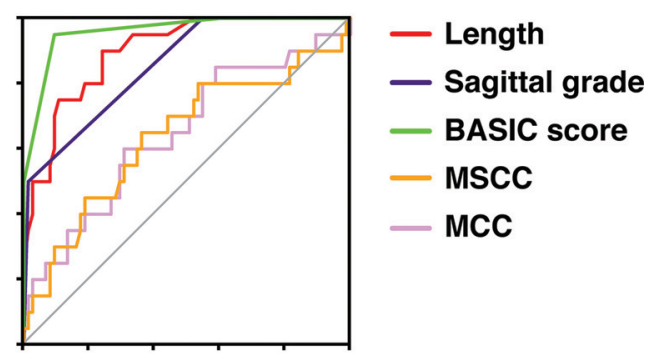

AIS A,B,C,D vs. E

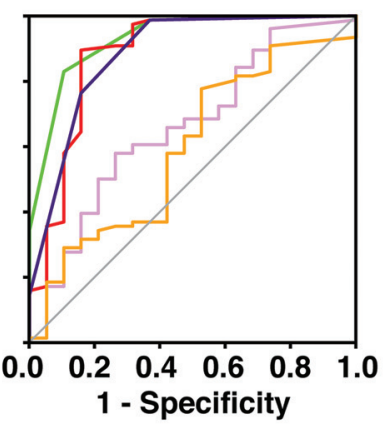

FIG 4. Receiver operating characteristic curves for the different MR imaging measures. The curves show the sensitivity and specificity of the different measures to predict AIS at discharge. AIS at discharge was dichotomized by using a sliding scale, resulting in 4 separate receiver operating characteristic curves (AIS A versus B, C, D, E; AIS A, B versus C, D, E; AIS A, B, C versus D, E; and AIS A, B, C, D versus E). The diagonal gray line represents a reference line that corresponds to random guessing. The further the receiver operating characteristic curves are located to the top left corner, the higher is the sensitivity and specificity of the measure in predicting the dichotomized AIS at discharge.

Table 5: Receiver operating characteristic analysis results

\begin{tabular}{lccc}
\hline & AUC & $\boldsymbol{P}$ Value & $95 \%$ Cl \\
\hline AIS A vs. B, C, D, E & & & \\
Length & 0.88 & $<.01$ & $0.80-0.96$ \\
Sagittal grade & 0.88 & $<.01$ & $0.79-0.97$ \\
BASIC score & 0.98 & $<.01$ & $0.95-1.00$ \\
MCC & 0.66 & .039 & $0.50-0.82$ \\
MSCC & 0.66 & .036 & $0.51-0.81$ \\
AIS A, B vs. C, D, E & & & \\
Length & 0.90 & $<.01$ & $0.83-0.97$ \\
Sagittal grade & 0.86 & $<.01$ & $0.77-0.94$ \\
BASIC score & 0.96 & $<.01$ & $0.92-1.00$ \\
MCC & 0.65 & .05 & $0.50-0.79$ \\
MSCC & 0.64 & .06 & $0.49-0.79$ \\
AIS A, B, C vs. D, E & & & \\
Length & 0.81 & $<.01$ & $0.72-0.89$ \\
Sagittal grade & 0.80 & $<.01$ & $0.71-0.89$ \\
BASIC score & 0.91 & $<.01$ & $0.85-0.97$ \\
MCC & 0.55 & .44 & $0.43-0.67$ \\
MSCC & 0.52 & .71 & $0.40-0.65$ \\
AIS A, B, C, D vs. E & & & \\
Length & 0.88 & $<.01$ & $0.77-0.99$ \\
Sagittal grade & 0.88 & $<.01$ & $0.79-0.98$ \\
BASIC score & 0.93 & $<.01$ & $0.86-0.99$ \\
MCC & 0.66 & .03 & $0.52-0.80$ \\
MSCC & 0.59 & .21 & $0.45-0.74$ \\
\hline Not AUC indictes & & &
\end{tabular}

Note:-AUC indicates area under the curve.

cerned that other factors may confound the prognostic validity of the BASIC score. For example, the decision to perform surgical decompression may be influenced by the presence and pattern of signal abnormality in the spinal cord, which could influence out- come. ${ }^{38-40}$ In addition, the extent of spinal cord compression with associated cord deformation may potentially confound BASIC grading. Our analysis confirms that the predictive validity of the BASIC score was maintained after correcting for potential interactions from surgical decompression and spinal cord compression.

Prior studies suggest MR imaging is most accurate at predicting outcomes when patients have evidence for very mild (normal cord signal) or very severe (intramedullary hemorrhage) injury. ${ }^{1,6,7,10,13,14,20}$ In contrast, tremendous variability in clinical outcomes has been described in the setting of intermediate degrees of injury. ${ }^{1}$ To specifically evaluate MR imaging measures and outcomes in this subgroup of patients from our cohort, we applied discriminant function analysis to patients with a BASIC score of 1-3 (patients with nonhemorrhagic intramedullary T2 signal hyperintensity; $n=72$ ). Even in this subpopulation, the BASIC score had a very high absolute correlation with the discriminant function (0.991), followed by the length of the lesion (0.416). Therefore, the prognostic capabilities of the BASIC score are not simply attributable to the ease of prognosis at the ends of the injury severity spectrum.

Limitations of our study primarily relate to the retrospective, single-institution study design. We are actively pursuing this subject further in a prospective fashion with longer clinical follow-up at multiple time points and more detailed outcome measures. Our technique was designed to look at the relationships of the various imaging metrics to each other and to clinical outcome (AIS at discharge). Although we believe that the current study is adequate for investigating these relationships, we realize that there are changes in neurologic impairment expected over a longer time course. In addition, in a future prospective study, more detailed outcome measures need to be included to more comprehensively capture neurologic function.

\section{CONCLUSIONS}

This study demonstrates the utility of applying NL-PCA for defining the relationship between MR imaging biomarkers in a complex clinical syndrome of cervical SCI. Independent, prospective studies are needed to validate our conclusion that intrinsic measures of spinal cord pathology on acute MR imaging, particularly the BASIC score, best predict neurologic impairment in acute SCI compared with measures of extrinsic compression. This analytic pipeline is suited for future patientlevel investigation and is amenable to inclusion of emerging potential biomarkers. Multidimensional approaches may also be useful for future prospective validation of imaging metrics 
derived from advanced quantitative techniques such as DTI, which are under active investigation for spinal cord pathology. ${ }^{26,41-43}$

Disclosures: Jenny Haefeli-RELATED: Grant: Craig H. Neilsen Foundation, Comments: Craig H. Neilsen postdoctoral scholar*; UNRELATED: Grants/Grants Pending: Craig H. Neilsen Foundation, Comments: Craig H. Neilsen postdoctoral scholar. William Whetstone-RELATED: Grant: Department of Defense, Comments: grant 20132016.* Sanjay Dhall—UNRELATED: Other: DePuy Spine, Globus Spine, Comments: speaking honoraria. Pavan Upadhyayula-RELATED: Grant: National Institutes of Health.* Jacqueline Bresnahan—RELATED: Grant: Department of Defense*; Support for Travel to Meetings for the Study or Other Purposes: Department of Defense*; UNRELATED: Grants/Grants Pending: National Institutes of Health, Department of Defense, Craig H. Neilsen Foundation. ${ }^{*}$ Michael Beattie—RELATED: Grant: Department of Defense Congressionally Directed Medical Research Programs - Spinal Cord Injury Research Program, Comments: grant SC120259, principal investigator.* Adam Ferguson—RELATED: Grant: National Institutes of Health/National Institute of Neurologic Disorders and Stroke, Wings for Life Foundation, Craig H. Neilsen Foundation, Comments: principal investigator on multiple grants cited in the paper that supported the work*; UNRELATED: Grants/Grants Pending: National Institutes of Health, Department of Defense, Veterans Affairs, Craig H. Neilsen Foundation, Wings for Life Foundation, Comments: principal investigator or co-investigator on many grants unrelated to the reported work. ${ }^{*}$ Jason Talbott—UNRELATED: Other: StemCells, Inc, Comments: member of data monitoring committee for clinical trial which is now ended. *Money paid to the institution.

\section{REFERENCES}

1. Bozzo A, Marcoux J, Radhakrishna M, et al. The role of magnetic resonance imaging in the management of acute spinal cord injury. J Neurotrauma 2011;28:1401-11 CrossRef Medline

2. Reier PJ, Lane MA, Hall ED, et al. Translational spinal cord injury research: preclinical guidelines and challenges. Handb Clin Neurol 2012;109:411-33 CrossRef Medline

3. Biering-Sørensen F, Alai S, Anderson K, et al. Common data elements for spinal cord injury clinical research: a National Institute for Neurological Disorders and Stroke project. Spinal Cord 2015;53: 265-77 CrossRef Medline

4. Talbott JF, Whetstone WD, Readdy WJ, et al. The Brain and Spinal Injury Center score: a novel, simple, and reproducible method for assessing the severity of acute cervical spinal cord injury with axial T2-weighted MRI findings. J Neurosurg Spine 2015;23:495-504 CrossRef Medline

5. Shimada K, Tokioka T. Sequential MR studies of cervical cord injury: correlation with neurological damage and clinical outcome. Spinal Cord 1999;37:410-15 CrossRef Medline

6. Schaefer DM, Flanders A, Northrup BE, et al. Magnetic resonance imaging of acute cervical spine trauma. Correlation with severity of neurologic injury. Spine (Phila Pa 1976) 1989;14:1090-95 CrossRef Medline

7. Ramón S, Domínguez R, Ramírez L, et al. Clinical and magnetic resonance imaging correlation in acute spinal cord injury. Spinal Cord 1997;35:664-73 CrossRef Medline

8. Miyanji F, Furlan JC, Aarabi B, et al. Acute cervical traumatic spinal cord injury: MR imaging findings correlated with neurologic outcome-prospective study with 100 consecutive patients. Radiology 2007;243:820-27 CrossRef Medline

9. Mihai G, Nout YS, Tovar CA, et al. Longitudinal comparison of two severities of unilateral cervical spinal cord injury using magnetic resonance imaging in rats. J Neurotrauma 2008;25:1-18 CrossRef Medline

10. Marciello MA, Flanders AE, Herbison GJ, et al. Magnetic resonance imaging related to neurologic outcome in cervical spinal cord injury. Arch Phys Med Rehabil 1993;74:940-46

11. Kulkarni MV, McArdle CB, Kopanicky D, et al. Acute spinal cord injury: MR imaging at 1.5 T. Radiology 1987;164:837-43 CrossRef Medline

12. Freund P, Weiskopf N, Ashburner J, et al. MRI investigation of the sensorimotor cortex and the corticospinal tract after acute spinal cord injury: a prospective longitudinal study. Lancet Neurol 2013; 12:873-81 CrossRef Medline

13. Flanders AE, Spettell CM, Tartaglino LM, et al. Forecasting motor recovery after cervical spinal cord injury: value of MR imaging. $R a$ diology 1996;201:649-55 CrossRef Medline

14. Flanders AE, Spettell CM, Friedman DP, et al. The relationship between the functional abilities of patients with cervical spinal cord injury and the severity of damage revealed by MR imaging. AJNR Am J Neuroradiol 1999;20:926-34 Medline

15. Fehlings $\mathrm{MG}$, Rao SC, Tator $\mathrm{CH}$, et al. The optimal radiologic method for assessing spinal canal compromise and cord compression in patients with cervical spinal cord injury. Part II: Results of a multicenter study. Spine (Phila Pa 1976) 1999;24:605-13 CrossRef Medline

16. Fehlings MG, Furlan JC, Massicotte EM, et al. Interobserver and intraobserver reliability of maximum canal compromise and spinal cord compression for evaluation of acute traumatic cervical spinal cord injury. Spine (Phila Pa 1976) 2006;31:1719-25 CrossRef Medline

17. Collignon F, Martin D, Lénelle J, et al. Acute traumatic central cord syndrome: magnetic resonance imaging and clinical observations. J Neurosurg 2002;96(1 Suppl):29-33 Medline

18. Chakeres DW, Flickinger F, Bresnahan JC, et al. MR imaging of acute spinal cord trauma. AJNR Am J Neuroradiol 1987;8:5-10 Medline

19. Bondurant FJ, Cotler HB, Kulkarni MV, et al. Acute spinal cord injury. A study using physical examination and magnetic resonance imaging. Spine (Phila Pa 1976) 1990;15:161-68 CrossRef Medline

20. Andreoli C, Colaiacomo MC, Rojas Beccaglia M, et al. MRI in the acute phase of spinal cord traumatic lesions: Relationship between MRI findings and neurological outcome. Radiol Med 2005;110: 636-45 Medline

21. Rao SC, Fehlings MG. The optimal radiologic method for assessing spinal canal compromise and cord compression in patients with cervical spinal cord injury. Part I: An evidence-based analysis of the published literature. Spine (Phila $\mathrm{Pa}$ 1976) 1999;24:598-604 CrossRef Medline

22. Furlan JC, Fehlings MG, Massicotte EM, et al. A quantitative and reproducible method to assess cord compression and canal stenosis after cervical spine trauma: a study of interrater and intrarater reliability. Spine (Phila Pa 1976) 2007;32:2083-91 CrossRef Medline

23. Budde MD, Kim JH, Liang HF, et al. Axonal injury detected by in vivo diffusion tensor imaging correlates with neurological disability in a mouse model of multiple sclerosis. NMR Biomed 2008;21: 589-97 CrossRef Medline

24. Bresnahan JC, Beattie MS, Stokes BT, et al. Three-dimensional computer-assisted analysis of graded contusion lesions in the spinal cord of the rat. J Neurotrauma 1991;8:91-101 CrossRef Medline

25. Tator $\mathrm{CH}$, Koyanagi I. Vascular mechanisms in the pathophysiology of human spinal cord injury. J Neurosurg 1997;86:483-92 CrossRef Medline

26. Rao J-S, Zhao C, Yang ZY, et al. Diffusion tensor tractography of residual fibers in traumatic spinal cord injury: a pilot study. $\mathrm{J} \mathrm{Neu}$ roradiol 2013;40:181-86 CrossRef Medline

27. Griffin JF, Davis MC, Ji JX, et al. Quantitative magnetic resonance imaging in a naturally occurring canine model of spinal cord injury. Spinal Cord 2015;53:278-84 CrossRef Medline

28. Kelley BJ, Harel NY, Kim CY, et al. Diffusion tensor imaging as a predictor of locomotor function after experimental spinal cord injury and recovery. J Neurotrauma 2014;31:1362-73 CrossRef Medline

29. Kim JH, Loy DN, Wang Q, et al. Diffusion tensor imaging at 3 hours after traumatic spinal cord injury predicts long-term locomotor recovery. J Neurotrauma 2010;27:587-98 CrossRef Medline

30. Mabray MC, Talbott JF, Whetstone WD, et al. Multidimensional analysis of magnetic resonance imaging predicts early impairment in thoracic and thoracolumbar spinal cord injury. J Neurotrauma 2016;33:954-62 CrossRef Medline

31. Ghodadra A, Alhilali L, Fakhran S. Principal component analysis of diffusion tensor images to determine white matter injury patterns 
underlying postconcussive headache. AJNR Am J Neuroradiol 2016; 37:274-78 CrossRef Medline

32. Jolliffe IT, Cadima J. Principal component analysis: a review and recent developments. Philos Trans A Math Phys Eng Sci 2016;374: 20150202 CrossRef Medline

33. Linting M, Meulman JJ, Groenen PJ, et al. Nonlinear principal components analysis: introduction and application. Psychol Methods 2007;12:336-58 CrossRef Medline

34. Linting M, van der Kooij A. Nonlinear principal components analysis with CATPCA: a tutorial. J Pers Assess 2012;94:12-25 CrossRef Medline

35. Cattell RB. The scree test for the number of factors. Multivariate Behav Res 1966;1:245-76 CrossRef Medline

36. Kaiser HF. The application of electronic computers to factor analysis. Educ Psychol Meas 1960;20:141-51 CrossRef

37. SyndromicPlot: Loadings Plot Generator. https://zenodo.org/record/ 47079\#.WB3iWzdGXMQ. Accessed March 7, 2016

38. Wilson JR, Singh A, Craven C, et al. Early versus late surgery for traumatic spinal cord injury: the results of a prospective Canadian cohort study. Spinal Cord 2012;50:840-43 CrossRef Medline
39. Fehlings MG, Vaccaro A, Wilson JR, et al. Early versus delayed decompression for traumatic cervical spinal cord injury: results of the Surgical Timing in Acute Spinal Cord Injury Study (STASCIS). PloS One 2012;7:e32037 CrossRef Medline

40. La Rosa G, Conti A, Cardali S, et al. Does early decompression improve neurological outcome of spinal cord injured patients? Appraisal of the literature using a meta-analytical approach. Spinal Cord 2004;42:503-12 CrossRef Medline

41. Wheeler-Kingshott CA, Hickman SJ, Parker GJ, et al. Investigating cervical spinal cord structure using axial diffusion tensor imaging. Neuroimage 2002;16:93-102 CrossRef Medline

42. Martin AR, Aleksanderek I, Cohen-Adad J, et al. Translating stateof-the-art spinal cord MRI techniques to clinical use: a systematic review of clinical studies utilizing DTI, MT, MWF, MRS, and fMRI. Neuroimage Clin 2016;10:192-238 CrossRef Medline

43. Talbott JF, Nout-Lomas YS, Wendland MF, et al. Diffusion-weighted magnetic resonance imaging characterization of white matter injury produced by axon-sparing demyelination and severe contusion spinal cord injury in rats. J Neurotrauma 2016;33:929-42 CrossRef Medline 
his erratum corrects the article "Multivariate Analysis of MRI Biomarkers for Predicting Neurologic Impairment in Cervical Spinal Cord Injury” (J. Haefeli, Mabray MC, Whetstone WD, et al. AJNR Am J Neuroradiol 2017;38:648-55 10.3174/ajnr.A5021).

In the original publication, there was an error in the Materials and Methods section on page 649 under the Image Analysis heading related to a description of the Brain and Spinal Injury Center (BASIC) score grading, which erroneously included a description of 6 distinct grades. The corrected version of text for this section is below and describes the correct 5 grades (grade 0 through grade 4 ) composing the BASIC score.

A neuroradiology fellow (M.C.M.) and attending physician (J.F.T.) performed consensus MR imaging ratings for all metrics while blinded to clinical outcome. The interrater reliability and BASIC axial MR imaging grading have been previously described as follows: ${ }^{4,30}$ grade 0 , no cord signal abnormality; grade I, T2 hyperintensity confined to GM; grade II, intramedullary T2 hyperintensity extending beyond the expected gray matter margins to involve spinal white matter but not involving the entire transverse extent of the spinal cord; grade III, T2 hyperintensity involving the entire axial plane of the spinal cord; grade IV, grade III injury with the addition of foci of T2 hypointensity consistent with hemorrhage. Sagittal grading was assigned as previously described as follows: grade I, no spinal cord signal abnormality; grade II, single-level T2 hyperintensity; grade III, >1 vertebral-level T2 signal hyperintensity; grade IV, T2 signal hyperintensity with areas of hypointensity representing hemorrhage. ${ }^{1,19}$ The greatest length (millimeters) of injury on sagittal T2 was measured as described in the National Institutes of Health/National Institute of Neurological Disorders and Stroke SCI Common Data Elements, Version 1.0. ${ }^{3}$ Maximum canal compromise (MCC) and maximum spinal cord compression (MSCC) assessed midsagittal images by dividing the anterior-posterior diameter of the canal (on sagittal T1 for MCC) and the anterior-posterior diameter of spinal cord (on sagittal T2 for MSCC) by the average of the canal or spinal cord above and below as previously described. ${ }^{8,15,16,22}$

The authors regret this error.

http://dx.doi.org/10.3174/ajnr.A7797 